\title{
Single-unit analysis of the human posterior hypothalamus and red nucleus during deep brain stimulation for aggressivity
}

\author{
Robert Micieli, BSc, ${ }^{1,3}$ Adriana Lucia Lopez Rios, MD, ${ }^{4}$ Ricardo Plata Aguilar, MD, ${ }^{4}$ \\ Luis Fernando Botero Posada, MD, ${ }^{4}$ and William D. Hutchison, PhD ${ }^{1-3}$ \\ Departments of ${ }^{1}$ Physiology and ${ }^{2}$ Surgery, University of Toronto; ${ }^{3}$ Krembil Research Institute, Toronto, Ontario, Canada; and \\ ${ }^{4}$ Centros Especializados de Hospital Universitario San Vicente Fundacion, Medellin-Rionegro, Colombia
}

\begin{abstract}
OBJECTIVE Deep brain stimulation (DBS) of the posterior hypothalamus (PH) has been reported to be effective for aggressive behavior in a number of isolated cases. Few of these case studies have analyzed single-unit recordings in the human $\mathrm{PH}$ and none have quantitatively analyzed single units in the red nucleus (RN). The authors report on the properties of ongoing neuronal discharges in bilateral trajectories targeting the $\mathrm{PH}$ and the effectiveness of DBS of the $\mathrm{PH}$ as a treatment for aggressive behavior.
\end{abstract}

METHODS DBS electrodes were surgically implanted in the PH of 1 awake patient with Sotos syndrome and 3 other anesthetized patients with treatment-resistant aggressivity. Intraoperative extracellular recordings were obtained from the ventral thalamus, $\mathrm{PH}$, and $\mathrm{RN}$ and analyzed offline to discriminate single units and measure firing rates and firing patterns. Target location was based on the stereotactic coordinates used by Sano et al. in their 1970 study and the location of the dorsal border of the RN.

RESULTS A total of 138 units were analyzed from the 4 patients. Most of the $\mathrm{PH}$ units had a slow, irregular discharge (mean $[ \pm \mathrm{SD}] 4.5 \pm 2.7 \mathrm{~Hz}, \mathrm{n}=68$ ) but some units also had a higher discharge rate $(16.7 \pm 4.7 \mathrm{~Hz}, \mathrm{n}=15)$. Two populations of neurons were observed in the ventral thalamic region as well, one with a high firing rate (mean $16.5 \pm 6.5 \mathrm{~Hz}$, $\mathrm{n}=5$ ) and one with a low firing rate (mean $4.6 \pm 2.8 \mathrm{~Hz}, \mathrm{n}=6$ ). $\mathrm{RN}$ units had a regular firing rate with a mean of $20.4 \pm$ $9.9 \mathrm{~Hz}$ and displayed periods of oscillatory activity in the beta range. $\mathrm{PH}$ units displayed a prolonged period of inhibition following microstimulation compared with RN units that were not inhibited. Patients under anesthesia showed a trend for lower firing rates in the PH but not in the RN. All 4 patients displayed a reduction in their aggressive behavior after surgery.

CONCLUSIONS During PH DBS, microelectrode recordings can provide an additional mechanism to help identify the $\mathrm{PH}$ target and surrounding structures to be avoided such as the RN. PH units can be distinguished from ventral thalamic units based on their response to focal microstimulation. The RN has a characteristic higher firing rate and a pattern of beta oscillations in the spike trains. The effect of the anesthetic administered should be considered when using microelectrode recordings. The results of this study, along with previous reports, suggest that PH DBS may be an effective treatment for aggression.

https://thejns.org/doi/abs/10.3171/2016.4.JNS141704

KEY WORDS deep brain stimulation; aggression; Sotos syndrome; intraoperative recordings; microelectrode recordings; microstimulation; functional neurosurgery

$\mathrm{S}$ ANO et al. were the first to report on the effectiveness of stereotactic radiofrequency lesions as a treatment for pathologically aggressive behavior. ${ }^{21}$ Significant reductions in aggressive behavior were observed in $95 \%$ of the cases in their series, with a fraction of their patients showing a complete absence of aggressive or violent behavior after surgery. Good clinical outcome was also obtained by Frazini et al., who performed deep brain stimulation (DBS) of the posterior hypothalamus (PH) for treatment-resistant aggressive behavior. ${ }^{7}$ Fur-

ABBREVIATIONS DBS = deep brain stimulation; $\mathrm{GABA}=\gamma$-aminobutyric acid; $\mathrm{GPi}=$ globus pallidus internus; $\mathrm{MOAS}=$ Modified Overt Aggression Scale; $\mathrm{PH}=$ posterior hypothalamus; QOLS = Quality of Life Scale; RN = red nucleus; $\mathrm{SNr}=$ substantia nigra.

SUBMITTED August 23, 2014. ACCEPTED April 6, 2016.

INCLUDE WHEN CITING Published online June 24, 2016; DOI: 10.3171/2016.4.JNS141704. 
ther reports have been made supporting the efficacy of the PH DBS procedure for treatment-resistant aggressivity, $, 9,13,24$ and based on these results, we offered to treat the aggressive and disruptive behavior associated with Sotos syndrome and other nongenetic causes using PH DBS. Alternate surgical options such as anterior capsulotomy and anterior cingulotomy have also been reported to improve aggression in patients, ${ }^{11}$ but the irreversible nature of placing thermolesions at these targets led us to opt for neuromodulation with DBS therapy.

Sotos syndrome is a rare genetic disorder caused by a mutation in the Nuclear SET Domain 1 (NSDI) gene that is found on the long arm of chromosome $5 .{ }^{14}$ It affects children at a young age and is characterized by macrocrania in the absence of megalencephaly, often with dolichocephaly. There are characteristic MRI changes such as extra CSF and midline changes (Fig. 1A and B). Characteristic facial features include a prominent forehead giving the impression of a receding hairline, deep-set eyes, and a triangular-shaped face, often with a pointed chin (Fig. 1C). Other features are increased birth weight and length, rapid growth in the early years, and developmental delay with advanced bone age. These physical features are accompanied by behavioral disturbances including anxiety, depression, sleep disturbance, tantrums, and aggression.

Among the studies that have reported on PH DBS, very few have analyzed single-unit recordings in the human PH and none have quantitatively analyzed recordings from the human red nucleus (RN). In addition to imaging techniques, microelectrode recordings can provide detailed information to help identify the $\mathrm{PH}$ target and surrounding structures to be avoided such as the RN during PH DBS surgery. This information can help ensure precise targeting of the PH and the avoidance of adverse effects.

In this case series, we describe and compare the properties of single-unit recordings in the human $\mathrm{PH}$, ventral thalamus, and $\mathrm{RN}$ in 4 patients. We also report on the effectiveness of PH DBS as a treatment for aggressive behavior in 3 young adults and for the aggression associated with Sotos syndrome.

\section{Methods}

\section{Stereotactic Surgery and Microelectrode Recordings}

All 4 patients underwent bilateral PH DBS surgery and all surgical and recording procedures were reviewed and approved by the ethics committee of the Hospital Universitario San Vicente de Paul Medellin/Rionegro. All patients exhibited chronic refractory auto- and heteroaggressive behavior, and further details of each case are presented in Table 1. Patients and/or their legal guardians provided free and informed consent to participate in the study. The tentative target of the trajectories was $1 \mathrm{~mm}$ behind the midcommissural point and $5 \mathrm{~mm}$ below the anterior commissural-posterior commissural line and 2 $\mathrm{mm}$ lateral to the lateral wall of the third ventricle (Fig. 1B). Microelectrode trajectories started $15 \mathrm{~mm}$ above the target at a $50^{\circ}-60^{\circ}$ anterior angle so that the recordings began in the ventral thalamus. Before microelectrode recordings were performed, the amount of anesthetic delivered was decreased to lighten the plane of anesthesia. The
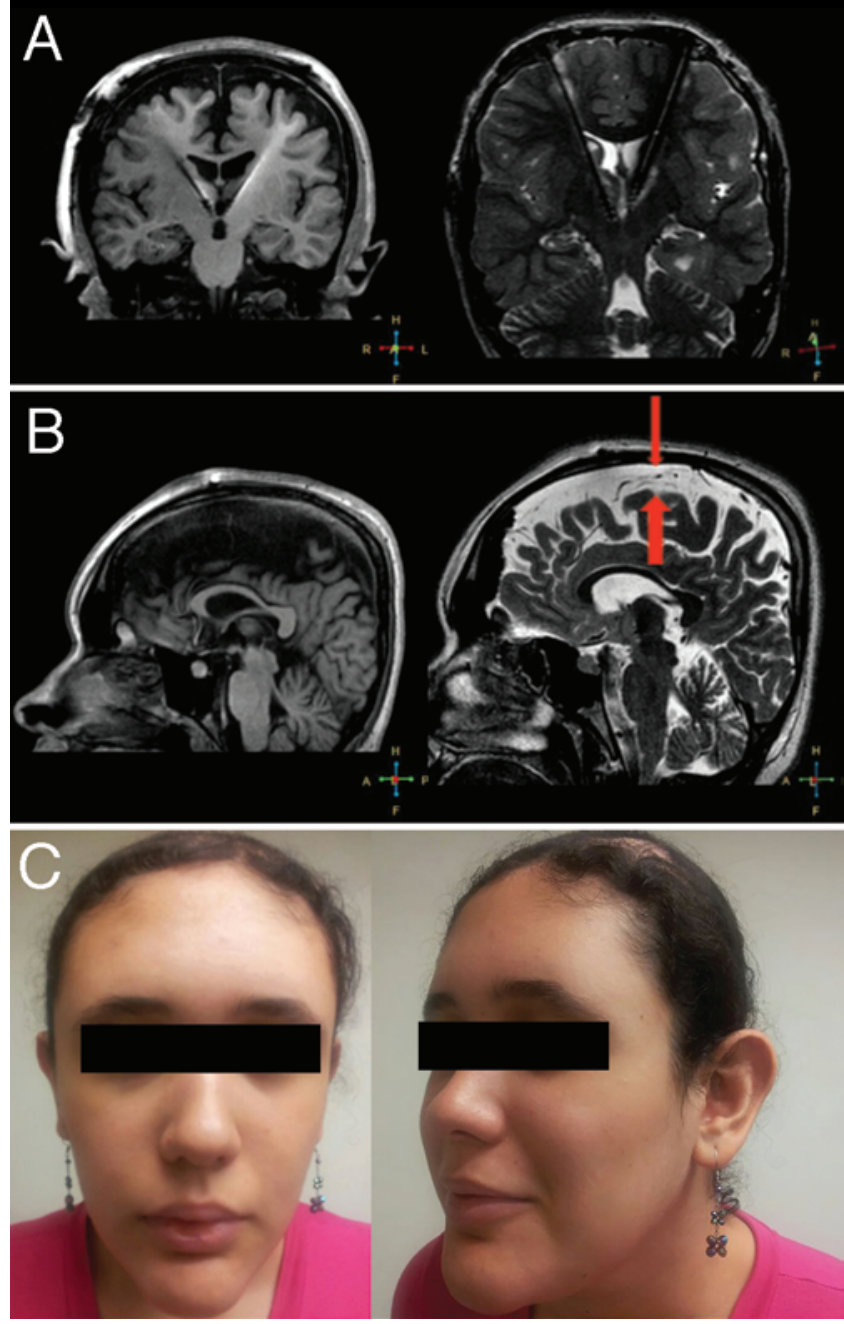

FIG. 1. Postoperative MR images and patient photos from Case 1 (Sotos syndrome), unless otherwise indicated. A: Coronal T1- and T2-weighted MR images. The coronal T2-weighted image is from Case 2 and shows the position of the bilateral electrodes and their relation to surrounding structures. B: Sagittal T1- and T2-weighted MR images show the wide subarachnoid space due to cortical atrophy (red arrows). C: Note the prominent forehead, receding hairline, and pointed chin characteristic of Sotos syndrome. Figure is available in color online only.

types and dosages of anesthetics administered are shown in Table 2. We recorded single units with 2 tungsten microelectrodes (about 25- $\mu \mathrm{m}$ tip length, approximately $0.2-0.4 \mathrm{M} \Omega$ impedance at $1 \mathrm{kHz}$ ) separated by $2 \mathrm{~mm}$ in the mediolateral direction (center and lateral) using the Frederick Haer Guideline 4000 LP+ system. There were no distinct landmarks identified at the target site, and we halted recording when RN neurons were identified (see Results). Microstimulation was performed through 1 or both of the microelectrodes at 2-mm intervals $(100 \mu \mathrm{A}$, $150-\mu \mathrm{sec}$ pulse width, $1-\mathrm{sec}$ train at $200 \mathrm{~Hz}$ ) to observe any sensory, motor, or autonomic side effects (tingling, pulling, or flushing, respectively). In some cases cells were tested for their response to focal microstimulation through the recording electrode itself (3-10 $\mu \mathrm{A}, 150-\mu \mathrm{sec}$ pulse width, $0.5-\mathrm{sec}$ train at $200 \mathrm{~Hz}$ ). The patients' limbs 
TABLE 1. Patient clinical information*

\begin{tabular}{|c|c|c|c|c|c|c|c|}
\hline $\begin{array}{l}\text { Case } \\
\text { No. }\end{array}$ & $\begin{array}{l}\text { Age } \\
\text { (yrs), } \\
\text { Sex }\end{array}$ & $\begin{array}{l}\text { Months on } \\
\text { Stimulation }\end{array}$ & $\begin{array}{c}\text { Associated } \\
\text { Diagnosis + Refractory } \\
\text { and Severe Aggression }\end{array}$ & $\begin{array}{c}\text { Age at } \\
\text { Onset of } \\
\text { Aggressivity } \\
\text { (yrs) }\end{array}$ & $\begin{array}{l}\text { No. of Aggressive } \\
\text { Episodes per Day } \\
\text { Before Surgery }\end{array}$ & $\begin{array}{c}\text { Medications Taken } \\
\text { Over } 2 \text { Yrs and Maximal } \\
\text { Doses (Aggressiveness) }\end{array}$ & Institutionalization \\
\hline 1 & $17, \mathrm{~F}$ & 7 & $\begin{array}{l}\text { Sotos syndrome, moderate cognitive } \\
\text { compromise, hypothyroidism }\end{array}$ & 2 & 3 & 6 & None \\
\hline 2 & $19, \mathrm{M}$ & 4 & $\begin{array}{l}\text { Epilepsy, temporal mesial sclerosis (post- } \\
\text { temporal lobectomy } 3 \text { years ago), } \\
\text { moderate cognitive compromise }\end{array}$ & 11 & $\begin{array}{l}\text { Innumerable } \\
\text { (every day) }\end{array}$ & 6 & None \\
\hline 3 & $10, M$ & 9 & $\begin{array}{l}\text { Tuberous sclerosis, epilepsy, West syn- } \\
\text { drome, severe cognitive compromise }\end{array}$ & 5 & 10 & 7 & Part-time \\
\hline 4 & $15, M$ & 3 & $\begin{array}{l}\text { Tuberous sclerosis, epilepsy, moderate } \\
\text { cognitive compromise }\end{array}$ & 5 & $\begin{array}{l}\text { Innumerable } \\
\text { (every day) }\end{array}$ & 5 & $24 \mathrm{hrs} /$ day \\
\hline
\end{tabular}

* All patients had both hetero- and auto-aggression.

were occasionally passively manipulated through brisk movements to identify any potential kinesthetic cells in the ventral thalamus. Examples of single-unit recordings for the ventral thalamus, $\mathrm{PH}$, and $\mathrm{RN}$ region are shown in Fig. 2.

Neuronal firing and local field potentials were obtained simultaneously from the microelectrode and the macroelectrode contact $10 \mathrm{~mm}$ away from the electrode tip. Recordings were amplified 5000-10,000 times and filtered at the source from 5 to $5000 \mathrm{~Hz}$. During the recordings, signals were monitored on loudspeakers and displayed on a computer screen. Recorded signals were digitized at 48 $\mathrm{kHz}$ and directly stored on a computer hard drive on the $\mathrm{LP}+$ system. Files were exported to Plexon format, and then imported into Spike2 (version 8, Cambridge Electronic Design).

\section{Single-Unit Analysis}

Raw extracellular recordings were digitally filtered offline from 200 to $3000 \mathrm{~Hz}$ and single units were then discriminated using a template-matching algorithm. Firing rate, pattern, and burst index were determined using an in-house burst detection algorithm-as described by Kaneoke and Vitek ${ }^{12}$-in the MatLab software suite (version 7, Mathworks). Single units with firing rates below $1 \mathrm{~Hz}$ were not included in the analysis. The data were not normally distributed and were compared using nonparametric statistical tests. When 3 or more means were compared the Kruskal-Wallis test was used. The DwassSteel-Critchlow-Fligner post hoc test was performed to further investigate statistically significant relationships.
When 2 means were compared, the Mann-Whitney U-test was used. All statistical tests were performed using the SAS software suite (version 9.4, SAS Institute). Statistical significance was accepted at $\mathrm{p}<0.05$ and a trend was identified for $\mathrm{p}$ values between 0.05 and 0.1 .

\section{Results}

\section{Group Recordings}

A total of 138 units from the 4 patients were analyzed, of which 11 were from the ventral thalamic region, 84 from the $\mathrm{PH}$, and 43 from the RN. Among the 4 patients, most of the PH units had a slow, irregular discharge (mean $[ \pm$ $\mathrm{SD}] 4.5 \pm 2.7 \mathrm{~Hz}, \mathrm{n}=68$ ) but some units also had a higher discharge rate $(16.7 \pm 4.7 \mathrm{~Hz}, \mathrm{n}=15)$. Two populations of neurons were observed in the ventral thalamic region as well, one with a high firing rate $(16.5 \pm 6.5 \mathrm{~Hz}, \mathrm{n}=5)$ and one with a low firing rate $(4.6 \pm 2.8 \mathrm{~Hz}, \mathrm{n}=6)$. No ventral thalamic units were detected in Patients 2, 3, and 4. In all patients, $\mathrm{RN}$ units had a regular firing rate (mean 20.4 $\pm 9.9 \mathrm{~Hz})$ with periods of oscillatory activity in the beta range $(13-20 \mathrm{~Hz})$ in the spike trains. No oscillatory spiking activity was evident in the $\mathrm{PH}$ or ventral thalamus. In several instances we noted larger and slower spikes firing with a regular pattern that were recorded before the faster and irregular RN units that often had beta activity. In general terms, we found the base of the ventral thalamus to be clearly found in the 1 awake case only and marked by the presence of units with low firing rates. Movement into the relatively silent $\mathrm{PH}$ was also inferred by the microelectrode tip position in the track relative to the tentative ana-

TABLE 2. Anesthetic use during procedure

\begin{tabular}{cccccc}
\hline Case No. & Type of Anesthetic Used During Surgery & Sevoflurane $(\mathrm{MAC})$ & Remifentanil $(\mu \mathrm{g} / \mathrm{kg} / \mathrm{min})$ & Dexmedetomidine $(\mu \mathrm{g} / \mathrm{kg} / \mathrm{hr})$ & Bispectral Index \\
\hline 1 & Awake & None & None & None & None \\
\hline 2 & General & 0.6 & 0.07 & None & None \\
\hline 3 & General & 0.3 & 0.07 & 0.3 & None \\
\hline 4 & General & 0.3 & 0.07 & 0.3 & $60-80$ \\
\hline
\end{tabular}

$\mathrm{MAC}=$ minimum alveolar concentration. 


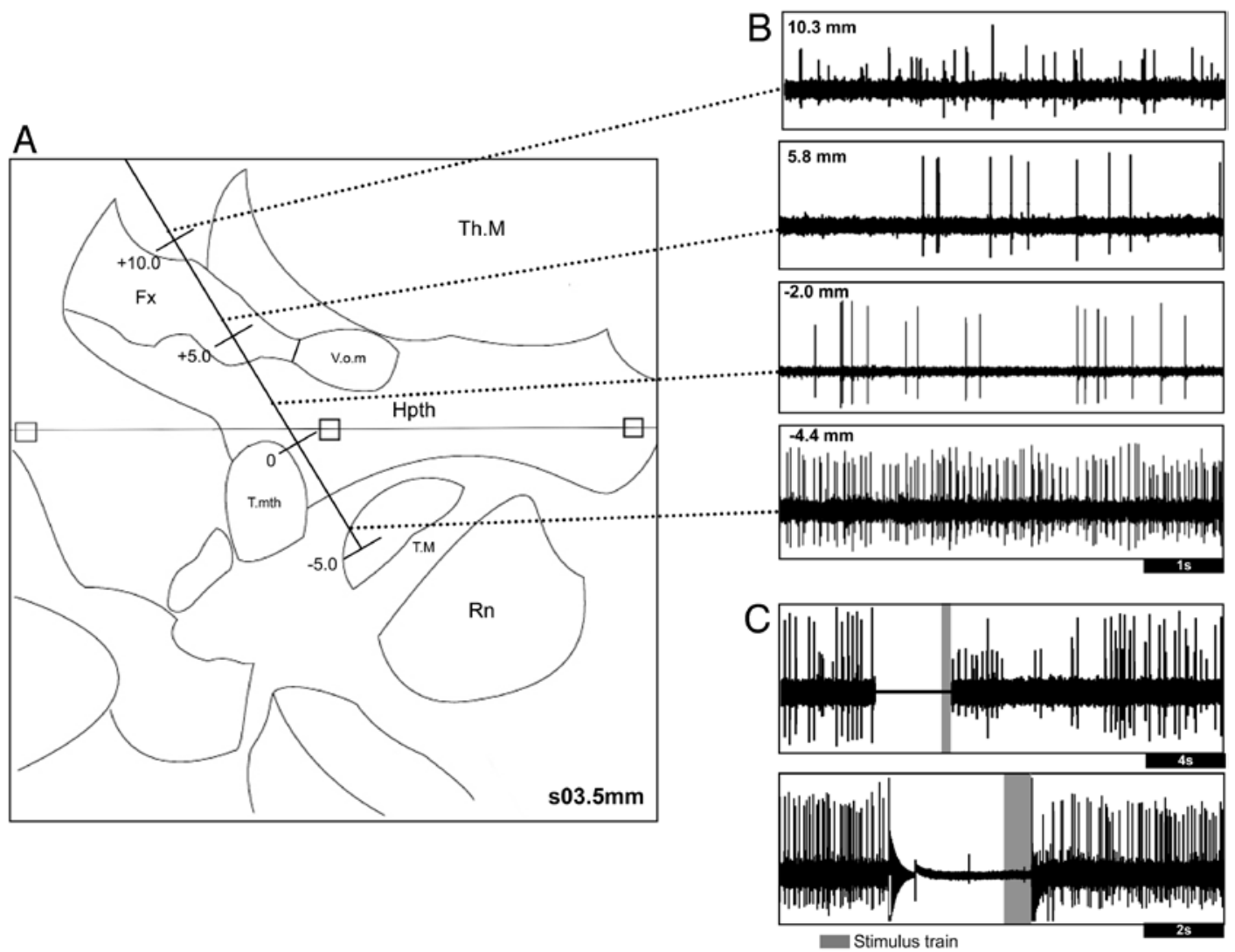

FIG. 2. Raw extracellular recordings of the ventral thalamus, PH, and RN during DBS. A: Depiction of a typical trajectory traversing the ventral thalamus, $\mathrm{PH}$ target, and ending in the RN. The map depicted is a sagittal plane projection $3.5 \mathrm{~mm}$ from the midline, based on the Schaltenbrand and Wahren human brain atlas. ${ }^{22} \mathrm{Fx}=$ fornix; Hpth = hypothalamus; $\mathrm{Th} . \mathrm{M}=$ thalamis opticus medialis; T.M = tractus retroflexus; T.mth = tractus mammillo-thalamicus; V.o.m = nucleus ventrooralis medialis. B: Recordings began 15 $\mathrm{mm}$ above the PH target and raw extracellular recordings at their corresponding depths are displayed. C: Units of the PH (upper) and RN (lower) were tested for their response to microstimulation. Microstimulation with a $0.5-\mathrm{sec}, 8-\mu \mathrm{A}, 200-\mathrm{Hz}$ train inhibited firing of $\mathrm{PH}$ units for a period of 8.9 seconds before they returned to their baseline firing rate (upper). Microstimulation with a 0.5 -sec, $10-\mu \mathrm{A}, 200-\mathrm{Hz}$ train did not inhibit firing of RN units (lower). The shaded gray region indicates the period during which the stimulus train is delivered.

tomical target. The entrance into the RN was quite clear and was assumed to be the end of the trajectory to avoid vessels in this area. In addition, in most cases a postoperative CT scan was obtained immediately after implantation to confirm the DBS electrodes were correctly positioned and the tip had not entered the third ventricle.

Following focal microstimulation, $\mathrm{PH}$ units displayed a period of prolonged inhibition of about 10 seconds before returning back to the baseline firing rate (Fig. $2 \mathrm{C}$ upper). No inhibition or characteristic response was observed in $\mathrm{RN}$ units following microstimulation (Fig. 2C lower).

A trend was identified between the dosage of anesthetic and the mean firing rate of the PH (Fig. 3). Patient 1, who was awake during surgery, showed a trend for a higher $\mathrm{PH}$ mean firing rate $(9.1 \pm 6.5 \mathrm{~Hz})$ than Patient $2(6.4 \pm$ $3.4 \mathrm{~Hz})$, Patient $3(4.0 \pm 2.4 \mathrm{~Hz})$, and Patient $4(8.3 \pm 6.1$ $\mathrm{Hz}$ ), who were lightly (Patient 2) or more heavily (Patients 3 and 4) anesthetized. The plane of anesthesia for Patient 4 , however, was lightened considerably before microelectrode recordings were performed. No significant difference was observed between the dosage of anesthetic and the mean firing rate of the $\mathrm{RN}(\mathrm{p}>0.1)$.

\section{Case 1}

The patient in Case 1 was female, 17 years of age at the time of the operation, and had Sotos syndrome, hypothyroidism, and moderate cognitive compromise with aggressivity for 15 years, averaging 3 episodes a day (Table 1). The mean firing rate of $\mathrm{PH}$ units $(9.1 \pm 5.2 \mathrm{~Hz}, \mathrm{n}=$ 19) was not significantly different from the mean firing rate of ventral thalamic units $(10.0 \pm 4.5 \mathrm{~Hz}, \mathrm{n}=11 ; \mathrm{p}>$ $0.1)$. RN units $(25.9 \pm 9.7 \mathrm{~Hz}, \mathrm{n}=4)$ showed a trend for a higher firing rate than PH units $(\mathrm{p}=0.06)$ and ventral thalamic units $(p=0.07)$. RN units also had a significantly lower median burst index $(1.1 \pm 0.09, \mathrm{n}=4)$ than ventral thalamic $(2.8 \pm 3.1, \mathrm{p}<0.05)$ and PH units $(1.7 \pm 0.04, \mathrm{n}=$ $19, \mathrm{p}<0.05)$. No significant difference was found between the median burst index of the $\mathrm{PH}$ and ventral thalamic units $(\mathrm{p}>0.1)$.

\section{Case 2}

Case 2 involved a 19-year-old man with epilepsy, temporal mesial sclerosis with a lobectomy 3 years prior, and moderate cognitive compromise. This patient had an 


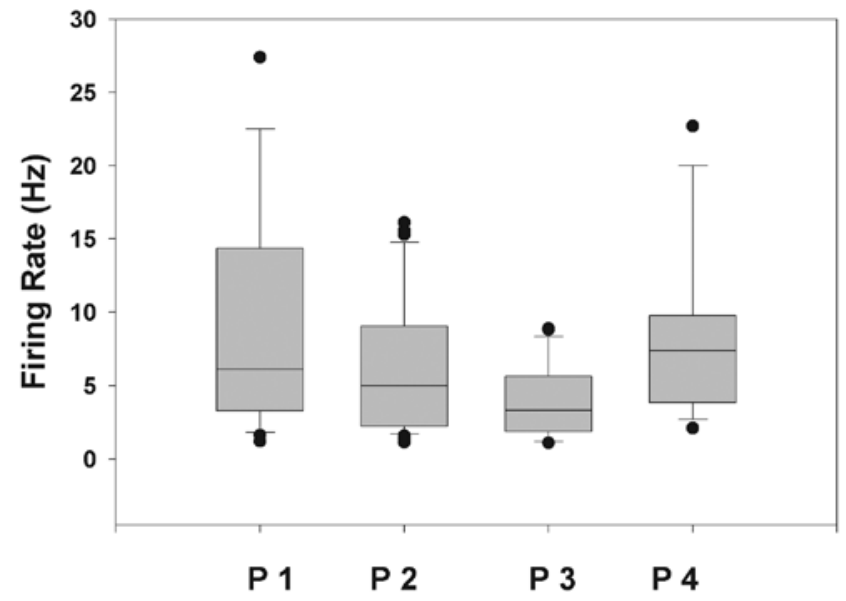

FIG. 3. Effect of anesthesia on PH firing rate. Patient $1(P 1)$ was awake and received no anesthetic. Patient 2 (P2) was lightly sedated, whereas Patients 3 (P3) and 4 (P4) were more heavily sedated. Compared with $\mathrm{P} 2$ and $\mathrm{P} 3$, the plane of anesthesia for $\mathrm{P} 4$ was lightened more before microelectrode recordings. Boxplot shows median firing rate (middle line in bars), 25th and 75th percentiles (thick gray bars), 5th and 95th percentiles (whiskers), and outliers (black dots).

8-year history of aggressive episodes many times a day. The mean firing rate of $\mathrm{PH}$ units $(6.4 \pm 3.4 \mathrm{~Hz}, \mathrm{n}=31)$ was lower than the firing rate of RN units $(18.3 \pm 6.8 \mathrm{~Hz}, \mathrm{n}=$ $12 ; \mathrm{p}<0.001)$. PH units $(7.5 \pm 19)$ also had a significantly higher median burst index compared with RN units (1.4 \pm $0.3 ; \mathrm{p}<0.05)$.

\section{Case 3}

A 10-year-old boy with a 5-year history of aggressive behavior, tuberous sclerosis, West syndrome (infantile epileptic spasms), and severe cognitive compromise had about 10 episodes per day. RN units had a higher mean firing rate $(20.8 \pm 8.5 \mathrm{~Hz}, \mathrm{n}=4)$ than $\mathrm{PH}$ units $(4.0 \pm 2.4$ $\mathrm{Hz}, \mathrm{n}=19 ; \mathrm{p}<0.05)$. No significant difference was found between the median burst index of PH units $(8.5 \pm 19)$ and RN units $(1.3 \pm 0.2 ; \mathrm{p}>0.1)$.

\section{Case 4}

A 15-year-old boy with 10 years of many aggressive episodes per day suffered from tuberous sclerosis epilepsy and moderate cognitive compromise. The mean firing rate of the PH units $(8.3 \pm 6.1 \mathrm{~Hz}, \mathrm{n}=15)$ was significantly lower than the mean firing rate of RN units $(23.0 \pm 7.0 \mathrm{~Hz}$, $\mathrm{n}=8$; $\mathrm{p}<0.001)$. PH units $(8.4 \pm 10.6)$ also had a significantly higher median burst index than RN units (1.2 \pm 0.2 ; $\mathrm{p}<0.05)$.

\section{Clinical Outcome}

The acute intraoperative autonomic effects and immediate postoperative anecdotal findings are reported in Table 3. In quantitative postoperative follow-up, aggressivity improved in these patients as assessed by the Modified Overt Aggression Scale (MOAS), and the Quality Of Life Scale (QOLS) scores improved, with follow-up periods at 3 and 27 months for each scale. MOAS improvement ranged from $78 \%$ to $97 \%$ and QOLS before surgery was 7-14 and the postoperative scores were 10-22. The QOLS improved from a range of $20-40$ to $60-90$ at follow-up. ${ }^{18}$

\section{Discussion}

With the exception of a few isolated case studies, $1,3,4,20$ very few reports have described single units in the human $\mathrm{PH}$. As an increasing number of studies report on the effectiveness of PH DBS for treatment-resistant aggression $^{5,7,9,13,24}$ and trigeminal autonomic cephalalgias such as cluster headache, 1,6,22 microelectrode recordings can help in the identification of the PH target and surrounding structures to be avoided, such as the RN. To our knowledge, no reports have quantitatively analyzed single units of the human RN.

Single units of the ventral thalamus can be distinguished from units of the $\mathrm{PH}$ based on their response to low-amplitude, high-frequency stimulation. Following stimulation, thalamic neurons display a brief period of burst activity followed by a period of prolonged silence before returning to their baseline firing pattern. ${ }^{2}$ In contrast, $\mathrm{PH}$ units display a period of prolonged inhibition before returning to the baseline firing rate. A similar but shorter inhibitory response is noted in single units of the internal segment of the globus pallidus internus (GPi) and substantia nigra $(\mathrm{SNr}){ }^{2}{ }^{215}$ This may be the result of stimulationinduced release of $\gamma$-aminobutric acid (GABA) from the axon terminals of GABAergic afferents originating in the putamen and striatum for the GPi, or the striatum and the external segment of the globus pallidus for the SNr. The $\mathrm{PH}$ receives GABAergic input from the basal forebrain

TABLE 3. Intraoperative and other clinical findings*

\begin{tabular}{cccc}
\hline $\begin{array}{c}\text { Case } \\
\text { No. }\end{array}$ & $\begin{array}{c}\text { Intraoperative Clinical Findings During } \\
\text { Macrostimulation }\end{array}$ & \multicolumn{1}{c}{ Complications } & Other Findings \\
\hline 1 & Patient was happy and speaking fluidly & Battery site infection & Patient was capable of speaking fluidly \\
\hline 2 & $10 \%$ change in blood pressure and heart rate & None & Patient's sleep cycle improved during the first month only \\
\hline 3 & $\begin{array}{c}20 \% \text { change in blood pressure and heart rate } \\
\text { as well as transient oculomotor movements }\end{array}$ & $\begin{array}{c}\text { Transient dystonia in left up- } \\
\text { per limb that improved with } \\
\text { changes in stimulation }\end{array}$ & $\begin{array}{c}\text { After surgery patient is making eye contact, obeying simple } \\
\text { orders, and making independent decisions such as tak- } \\
\text { ing time to eat and going to the washroom }\end{array}$ \\
\hline 4 & None & None & $\begin{array}{c}\text { Patient is more relaxed, capable of establishing empathy } \\
\text { with the examiner, and able to follow simple rules }\end{array}$ \\
\hline
\end{tabular}

* There were no changes in medication in any of the 4 patients. 
and the preoptic-anterior hypothalamic neurons, ${ }^{8}$ and the stimulation-induced GABA release from the terminals of these axons may provide a similar explanation for the inhibitory response observed following stimulation. Outside of their response to microstimulation, recordings of the ventral thalamus are not distinguished by characteristic differences from recordings of the PH. Microstimulation, therefore, provides an effective way of delineating single units from these 2 brain regions.

$\mathrm{RN}$ units can be distinguished from $\mathrm{PH}$ units by regular and faster discharge rates around $20 \mathrm{~Hz}$ and oscillatory activity in the beta range (13-20 Hz). Beta oscillations were not observed in ventral thalamic or PH units and may be related to the RN motor function. Under light or no sedation, $\mathrm{RN}$ units fired in a less bursty fashion than $\mathrm{PH}$ units. These results are consistent with the qualitative description of RN units made by Lefranc et al., who explored DBS of the RN for cerebellar tremor. ${ }^{17}$ They observed almost no bursting pattern and high background activity in RN units. However, Lefranc et al. made only qualitative and no quantitative observations to support their findings. The slower and more regular cells recorded dorsal to the faster neurons may be magnocellularis cells of the RN or possibly adjacent nucleus basalis neurons.

Following microstimulation, RN units do not display an inhibitory response. A possible explanation for this is that the $\mathrm{RN}$, which receives input from the trigeminal nucleus and the interpositus nucleus of the cerebellum, ${ }^{10}$ and also relays input from the cortex to the cerebellum via the rubro-olivary tract (climbing fiber input) ${ }^{16}$ does not receive input from GABAergic afferents. This response to microstimulation can therefore provide an additional mechanism in identifying RN from PH units.

Without the influence of anesthetic, the mean $\mathrm{PH}$ firing rate in Patient 1 was $9.1 \mathrm{~Hz}$, compared with the $10-24 \mathrm{~Hz}$ range previously obtained for the human $\mathrm{PH} \mathrm{H}^{1,3,4,20}$ Variations in the firing rate may be due to the difficulty in discriminating the PH from ventral thalamic units using only microelectrode recordings and not response to microstimulation. Variations may also be explained by differences in single-unit isolation during offline analysis.

We also identified a trend between the $\mathrm{PH}$ firing rate and the dosage of the anesthetic administered. The firing rate of the $\mathrm{RN}$, however, was not affected by the dosage of the anesthetic. This difference may be explained by the fact that the plane of anesthesia was decreased before microelectrode recordings began. Because the RN was located at the end of the trajectory, the dosage of anesthetic administered when RN units were encountered could have decreased to an amount that had little or no effect on their firing rate. $\mathrm{PH}$ units were encountered earlier on and therefore at a higher dosage of anesthetic that may have been capable of influencing the $\mathrm{PH}$ firing rate.

High-frequency stimulation of the $\mathrm{PH}$ was effective in attenuating the aggressive behavior associated with Sotos syndrome and other nongenetic causes. All 4 patients benefitted from PH DBS with a reduction in aggressive episodes after surgery, allowing them to return home from institutionalized care or interact more normally in public spaces. Longer-term follow-up on a larger series will be reported elsewhere. Good clinical outcome was obtained by Sano et al. in their 1970 study in which stereotactic lesioning of the posteromedial hypothalamus was effective in patients with pathologically aggressive behavior. The exact mechanism of the therapeutic action of PH DBS, however, is still unknown. One of the most common interpretations is the functional inhibition of target areas with high-frequency stimulation. The hypothalamus acts as a relay for the motor output of the limbic system ${ }^{19,21,23}$ and interrupting its function with DBS could block the expression of unwanted limbic output.

Along with the findings of previous studies, our results suggest PH DBS can be a treatment option for patients with treatment-resistant aggressivity. The reversibility of the DBS procedure makes it an attractive alternative to the hypothalamotomies performed by Sano et al. in their 1970 experiment. Further studies should be performed to confirm the efficacy of this procedure and the results obtained in this limited case series.

\section{Conclusions}

During PH DBS, microelectrode recordings can provide an additional mechanism to help identify the PH target and surrounding structures to be avoided such as the $\mathrm{RN}$. PH units can be distinguished from ventral thalamic units based on their response to focal microstimulation. Compared with the PH, RN units have a regular and higher discharge rate, oscillations in the beta range, and no inhibitory response following microstimulation. The effect of the anesthetic administered should be considered when using microelectrode recordings. The results of this study, along with previous reports, suggest that PH DBS may be an effective treatment for aggression.

\section{Acknowledgments}

We thank Dr. Neil Mahant for developing the custom MATLAB scripts. Support for this study was received from the Canadian Institute for Health Research (grant no. CIHR MOP 98006), the Dystonia Medical Research Foundation, and Medtronic Inc. (W.D.H.). R.M. was supported by the Undergraduate Research Opportunity Program at the University of Toronto.

\section{References}

1. Bartsch T, Pinsker MO, Rasche D, Kinfe T, Hertel F, Diener $\mathrm{HC}$, et al: Hypothalamic deep brain stimulation for cluster headache: experience from a new multicase series. Cephalalgia 28:285-295, 2008

2. Birdno MJ, Tang W, Dostrovsky JO, Hutchison WD, Grill WM: Response of human thalamic neurons to high-frequency stimulation. PLoS One 9:e96026, 2014

3. Cordella R, Carella F, Franzini A, Marras C, Villani F, Messina $\mathrm{G}$, et al: Intraoperative microrecordings in the posterior hypothalamus of anaesthetized humans with aggressive behaviour. Neurol Sci 31:183-188, 2010

4. Cordella R, Carella F, Leone M, Franzini A, Broggi G, Bussone $\mathrm{G}$, et al: Spontaneous neuronal activity of the posterior hypothalamus in trigeminal autonomic cephalalgias. Neurol Sci 28:93-95, 2007

5. Franzini A, Broggi G, Cordella R, Dones I, Messina G: Deep-brain stimulation for aggressive and disruptive behavior. World Neurosurg 80:S29.e11-S29.e14, 2013

6. Franzini A, Ferroli P, Leone M, Broggi G: Stimulation of the posterior hypothalamus for treatment of chronic intrac- 
table cluster headaches: first reported series. Neurosurgery 52:1095-1101, 2003

7. Franzini A, Marras C, Ferroli P, Bugiani O, Broggi G: Stimulation of the posterior hypothalamus for medically intractable impulsive and violent behavior. Stereotact Funct Neurosurg 83:63-66, 2005

8. Gritti I, Mainville L, Jones BE: Projections of GABAergic and cholinergic basal forebrain and GABAergic preopticanterior hypothalamic neurons to the posterior lateral hypothalamus of the rat. J Comp Neurol 339:251-268, 1994

9. Hernando V, Pastor J, Pedrosa M, Peña E, Sola RG: Lowfrequency bilateral hypothalamic stimulation for treatment of drug-resistant aggressiveness in a young man with mental retardation. Stereotact Funct Neurosurg 86:219-223, 2008

10. Holstege G, van Ham JJ, Tan J: Afferent projections to the orbicularis oculi motoneuronal cell group. An autoradiographical tracing study in the cat. Brain Res 374:306-320, 1986

11. Jiménez F, Soto JE, Velasco F, Andrade P, Bustamante JJ, Gómez P, et al: Bilateral cingulotomy and anterior capsulotomy applied to patients with aggressiveness. Stereotact Funct Neurosurg 90:151-160, 2012

12. Kaneoke Y, Vitek JL: Burst and oscillation as disparate neuronal properties. J Neurosci Methods 68:211-223, 1996

13. Kuhn J, Lenartz D, Mai JK, Huff W, Klosterkoetter J, Sturm V: Disappearance of self-aggressive behavior in a braininjured patient after deep brain stimulation of the hypothalamus: technical case report. Neurosurgery 62:E1182, 2008

14. Kurotaki N, Imaizumi K, Harada N, Masuno M, Kondoh T, Nagai T, et al: Haploinsufficiency of NSD1 causes Sotos syndrome. Nat Genet 30:365-366, 2002

15. Lafreniere-Roula M, Hutchison WD, Lozano AM, Hodaie M, Dostrovsky JO: Microstimulation-induced inhibition as a tool to aid targeting the ventral border of the subthalamic nucleus. J Neurosurg 111:724-728, 2009

16. Larochelle L, Bedard P, Boucher R, Poirier LJ: The rubro-olivo-cerebello-rubral loop and postural tremor in the monkey. J Neurol Sci 11:53-64, 1970

17. Lefranc M, Manto M, Merle P, Tir M, Montpellier D, Constant JM, et al: Targeting the red nucleus for cerebellar tremor. Cerebellum 13:372-377, 2014

18. Lopez Rios AL, Hutchison WD, Gil Restropo C, Aristizabal Gaviria A, Botero Posada LF: Posterior hypothalamus deep brain stimulation in 8 refractory aggressivity patients using an ideal multifactorial approach, in $\mathbf{1 4}^{\text {th }}$ Meeting of the
World Society for Stereotactic and Functional Neurosurgery, Mumbai. WSSFN, 2015, Abstract \#0131

19. Ramamurthi B: Stereotactic operation in behaviour disorders. Amygdalotomy and hypothalamotomy. Acta Neurochir Suppl 44:152-157, 1988

20. Sani S, Shimamoto S, Turner RS, Levesque N, Starr PA: Microelectrode recording in the posterior hypothalamic region in humans. Neurosurgery 64 (3 Suppl):ons161-ons169, 2009

21. Sano K, Mayanagi Y, Sekino H, Ogashiwa M, Ishijima B: Results of stimulation and destruction of the posterior hypothalamus in man. J Neurosurg 33:689-707, 1970

22. Sillay KA, Sani S, Starr PA: Deep brain stimulation for medically intractable cluster headache. Neurobiol Dis 38:361-368, 2010

23. Sokolowski K, Corbin JG: Wired for behaviors: from development to function of innate limbic system circuitry. Front Mol Neurosci 5:55, 2012

24. Torres CV, Sola RG, Pastor J, Pedrosa M, Navas M, GarcíaNavarrete E, et al: Long-term results of posteromedial hypothalamic deep brain stimulation for patients with resistant aggressiveness. J Neurosurg 119:277-287, 2013

\section{Disclosures}

The authors report no conflict of interest concerning the materials or methods used in this study or the findings specified in this paper.

\section{Author Contributions}

Conception and design: Hutchison, Lopez Rios. Acquisition of data: Hutchison, Lopez Rios, Plata Aguilar, Botero Posada. Analysis and interpretation of data: Hutchison, Micieli. Drafting the article: Micieli. Critically revising the article: Hutchison, Micieli. Reviewed submitted version of manuscript: Hutchison, Micieli, Lopez Rios. Approved the final version of the manuscript on behalf of all authors: Hutchison. Statistical analysis: Micieli. Study supervision: Hutchison, Lopez Rios. Neuroanesthetist: Plata Aguilar, Botero Posada.

\section{Correspondence}

William D. Hutchison, Toronto Western Research Institute, 399 Bathurst St., 12MC417, Toronto, Canada M5T 2S8. email: whutch@uhnres.utoronto.ca. 